\title{
Re-Voltar ao Tekoha: memórias dos jovens Avá-Guarani
}

\author{
Re-Return to Tekoha, memories of young Ava-Guarani
}

\author{
Cynthia Franceska Cardoso*
}

\begin{abstract}
Resumo:
Desvelar a memória dos povos originários é fazer um giro ao passado, é exercitar o porvir em si, é trazer à tona dezenas de lembranças transmitidas por séculos de geração a geração. É se valer do passado para compreender o presente e forjar o futuro. É re-existir ao resistir por séculos e séculos. É aprender com as xejary'i, os xeramoi, os jovens e crianças que os percalços existem há uns cinco séculos, assim como as estratégias lançadas para transpô-los. As memórias ora apresentadas são fruto da pesquisa de pós-doutorado realizada em parte do território Avá-Guarani, localizado na região Oeste do Paraná. Valendo-nos da história oral, enquanto recurso metodológico, ancorado nas narrativas, nas histórias de vida, nas lembranças, bem como nos teóricos norteadores, compreendemos que no caminhar das histórias de vida relatadas pelos Avá-Guarani do Oeste do Paraná, há algo precioso que os karaí não puderam subtrair-lhes: a memória ancestral. É a respeito desta que aqui se tratará.
\end{abstract}

Palavras-chave: Memórias, resistência; re-existência; jovens; Avá-Guarani.

Abstract: Unveiling the memory of the original peoples is turning the past, exercising the future itself, and bringing out dense memories transmitted from centuries through generations. It is the most recent value for understanding the present and forging the future. It is to re-exist by resisting for centuries and centuries. It is learning from xejary'i, the xeramoi, young people and children that mishaps have existed for about five centuries, as well as the strategies initiated to overcome them. Memories cited are the result of post-doctoral research carried out in part of the Avá-Guarani territory, located in the western region of Paraná. Using oral history, as a methodological resource, anchored in narratives, life stories, memories, as well as theoretical guides, we understand that in the course of the life stories related to the avá-guarani of western Paraná, there is something precious that the karai could not remove: an ancestral memory. It is in respect of that we treat.

Keywords: Memories, resistance; re-existence; young; Avá Guarani

* Centro Universitário do Vale do Ribeira - UNIVR/UNISEPE 


\section{Introdução}

Ao pensarmos neste texto ${ }^{1}$, pensamos, sobretudo, em reverberar a presença do povo Avá-Guarani, do Oeste do Paraná, por vezes, silenciada nas formas mais abomináveis, desde o estupro de mulheres, assassinatos e a ameaças à vida de lideranças, até a omissão e a conivência histórica do Estado brasileiro, resultante da violação de direitos sociais básicos, como a desnutrição infantil, a fome, a miséria, a ausência e/ou oferta precária de serviços de saúde e educação, entre outros elementos utilizados tanto pelo Estado quanto por terceiros, a saber, fazendeiros e comerciantes da região, no intento de aniquilá-los. Silenciamentos impressos em suas memórias, lembranças e histórias de vida forjam o arcabouço da resistência e do re-existir.

Ao nos aproximarmos das histórias de vida do povo Guarani, especificamente, dos Avá-Guarani habitantes na região dos municípios de Santa Helena, São Miguel do Iguaçu, Itaipulândia, Diamante d’Oeste, Guaíra e Terra Roxa, fomos lançados à reflexão acerca da sua resistência e re-existência frente aos processos seculares de opressão, subjugação, espoliação a que foram e são submetidos.

As memórias resgatadas nos relatos dos xeramoi (anciãos) e xejary'i (anciãs) e dos jovens, nos permitiu imergir num universo em que a sua existência ameaçava, desde os primeiros contatos desse povo com os invasores da América Latina e, ainda hoje, projetos políticos e econômicos distintos da sua visão de mundo, do seu ñandereko (modo de viver Guarani).

As lembranças vividas no presente e vislumbradas no porvir dão sentido à sua existência. O sofrimento vívido em suas memórias é consequência do passado que ainda persiste em seu presente e, de alguma forma, está projetado em seu futuro. Carregam consigo a dor da re-existência cultural, social, histórica e política sublimada pelo resistir ordinário. A insistente permanência dos Avá em seu território ancestral transnacional o qual, inicialmente,

\footnotetext{
${ }^{1}$ O presente texto é fruto da pesquisa de pós-doutorado, financiada pela Capes, realizada entre os anos de 20182019, desenvolvida no âmbito do projeto de pesquisa multidisciplinar intitulado "Conflitos e resistências para a conquista e demarcação de Terras Indígenas no Oeste do Paraná: os caminhos e as expressões do fortalecimento das lideranças e da cultura Guarani” do qual participaram: Universidade Estadual de Maringá (UEM), Universidade Estadual de Londrina (UEL), Universidade Estadual do Centroeste (UNICENTRO), e a Universidade "Luiz de Queiroz" (ESALQ).
} 
abrangia desde a Bolívia, Paraguai, Argentina e Brasil simboliza o continuar reelaborando modos de viver frente às diferentes perseguições vivenciadas.

Intentando ampliar as vozes do povo Avá, registramos algumas dessas estratégias de resistência e re-existência, a partir do resgate de memórias, das narrativas, tanto dos mais velhos quanto dos jovens, de suas histórias de vida e lembranças. Por essa razão, estruturamos o texto em três momentos: inicialmente, apresentamos alguns conceitos norteadores da metodologia utilizada que nos possibilitaram apreender quais os processos sociais, históricos, políticos e econômicos que permearam as histórias de vida dos Avá; em seguida, retomamos a existência perdurável do povo Guarani no Brasil, sobretudo a dos Avá na região oeste do Paraná; num terceiro momento, delineamos, a partir dos relatos, a transmissão de conhecimentos dos xeramoi e das xejary'i aos jovens, enquanto estratégia de luta e permanência no e pelo território e, por fim, apresentamos algumas considerações a respeito da sua luta incessante pela sobrevivência.

\section{Histórias nas memórias}

Revisitar o passado para desvelar o presente e ensejar o futuro a partir das memórias lembradas pelos xeramoi e xejary'i e pelos jovens, nos permitiu maior compreensão do universo Avá-Guarani, da sua permanência e resistência em seus territórios ancestrais, no oeste do Paraná.

Registrar seus relatos, suas narrativas e histórias de vida, enquanto recursos metodológicos, foi almejar dar escuta a um povo excluído social, política e economicamente há séculos.

Seguindo essa lógica e, a fim de reafirmarmos a sua existência imemorial na região, recorremos à história oral, de vida, enquanto recurso metodológico, relacionando os referenciais teóricos às lembranças advindas das memórias dos mais velhos e dos jovens coletadas durante a realização do trabalho de campo.

Observando-se que a tradição da escrita é bastante recente entre os povos originários, a história oral tem grande valia quando se trata de registrar a cultura e o modo de vida. A apropriação da história oral, enquanto recurso metodológico para a pesquisa, ancorouse na perspectiva de que o passado, revisitado a partir do resgate da memória, por meio das narrativas dos entrevistados, está no presente vivido pelos sujeitos sociais e, em parte, na 
prospecção do seu futuro. E, ainda, possibilita confrontar fontes escritas e orais (ICHIKAWA, SANTOS, 2006).

\begin{abstract}
É no tempo, tempo este que é aquele de um determinado grupo, que ele procura encontrar ou ainda reconstituir a lembrança e é no tempo que ele se apoia. O tempo e só ele pode desempenhar esse papel à medida em que o representamos como um meio contínuo que não mudou e que permaneceu o mesmo hoje como ontem de maneira que podemos encontrar ontem dentro de hoje. [...]. Quando dizemos que um indivíduo se conduz com a ajuda da memória do grupo, é necessário entender que essa ajuda não implica na presença atual de um ou vários de seus membros. Com efeito, continuo a sofrer a influência de uma sociedade ainda que tenha me distanciado: basta que carregue comigo em meu espírito tudo o que me capacite para me posicionar do ponto de vista de seus membros, de me envolver em seu meio e em seu próprio tempo, e de me sentir no coração do grupo (HALBWACHS, p. 120, 1990).
\end{abstract}

É oportuno, inicialmente, apresentarmos algumas ideias e conceitos utilizados neste texto. A memória é compreendida a partir de autores como Le Goff (2003), Yates (2007), Halbwachs (1990), Ichikawa (2006; 2018), os quais, de modo geral, compreendem a memória enquanto recurso para avançar no futuro, ou seja, resgatando a existência do passado de um povo, resgatamos, em certa medida, a identidade coletiva dos mesmos, seus anseios, seu modo de viver, suas expectativas, esperanças e planos quanto ao futuro.

As memórias são construídas coletivamente e individualmente, isto porque cada indivíduo constrói a sua própria história, recebe as informações e as processa de acordo com o que viveu durante a sua vida, reconhecendo, dessa forma, a sua luta e a preservação da cultura.

O resgate da memória nos permite analisar que as narrativas constroem o presente a partir do vivido ou relatado a respeito do ou no passado. É o passado que dá a tônica do presente e forja o futuro. Neste território as histórias de vida são tecidas a partir, também, das narrativas transmitidas por meio do relembrar das memórias dos mais velhos em diversos momentos aos jovens.

A memória, neste sentido, de acordo com Ichikawa e Santos (2018), é o resgate do passado apresentado e vivido de certa maneira no presente, é um instrumento para o agir social e, desta forma, uma fonte de poder, dando sentido ao presente, num devir. Nos relatos, nas lembranças "percebemos a interligação entre passado, presente e futuro [...]. Assim conhecermos o passado é tão relevante quanto desmembrar o presente, para construirmos o futuro" (GOUVÊA, CABANA, ICHIKAWA, p. 313-14, 2018). 
A memória faz parte da vida social, assim como da individual. Interessa tanto ao indivíduo quanto à sociedade da qual faz parte, isto porque a memória também é poder, do qual depende o seu registro, é apropriar-se do tempo. Dessa forma, apagar a memória é apagar o poder (LE GOFF, 2003).

Ao nos valermos da re-existência e da resistência, enquanto modos de enfrentamento das adversidades criados pela população indígena desde o contato com os não indígenas, aproximamo-nos de Limbert (2015) e Amaral (2016). O uso do prefixo re intenciona reforçar a sua existência, enquanto resistência social e cultural, por meio da reinvenção de novas formas de viver, de sobreviver, para resistir à exploração social e ambiental sofrida desde então.

A partir de Bartolomeu Melià (1988a, 1988b), Egon Schaden (1974), Maria Inês Ladeira (2001), Brant de Carvalho (2013), Alcântara (2019) lançamos luzes ao passado e ao presente do povo Avá-Guarani, bem como à sua cultura e aos processos de colonização na região oeste do Paraná.

Os dados primários foram produzidos por meio do uso de roteiros de observação e de entrevistas direcionadas, utilizadas durante a pesquisa de campo, realizada em três viagens às aldeias, as quais duraram, aproximadamente, três dias. No município de Santa Helena foram visitadas duas aldeias: Curva Guarani e Araporã. Em São Miguel do Iguaçu, a Terra Indígena Oco'y. Em Diamante do Oeste, a Terra Indígena Añe Te Te. Na região de Guaíra, a aldeia Jevy e a Porã. Por fim, em Terra Roxa, Yvyra ty Porã.

Esses recursos permitiram, conforme Ichikawa e Santos (2006), compreender que o passado narrado por atores, até então, sem escuta, continua no presente. Proporcionaram visualizar quais as estratégias de luta, resistência e sobrevivência relatadas no decorrer das entrevistas. Também possibilitaram a reflexão conjunta com os jovens, os xeramoi e xejary'i e as xejary'i, a respeito da história, do modo de ser e viver Avá-Guarani, ensejando seu protagonismo e emancipação num processo de construção coletiva.

\section{Re-existências Ava Guarani}

Recordar alguns processos históricos, políticos e sociais, desde o tempo da colonização da América Latina, relacionando-os aos relatos dos xeramoi e xejary'i e dos jovens, 
nos aproxima dos interesses políticos e econômicos que ainda permeiam o cotidiano dos AváGuarani no oeste do Paraná.

Os Guarani são nominados diferentemente de acordo com a região em que vivem, embora compartilhem, de modo geral, de uma mesma cultura que os une enquanto povo, também possuem significativas diferenças na língua, em rituais, cestaria, etc. (LINI, 2016). O povo Guarani pertence ao tronco linguístico Tupi e à família linguística Tupi-Guarani, sendo dividido em três subgrupos: Kaiova, Nhandéva (Xiripa, Chiripa, Ava) e Mbya.

A sua presença no continente é datada em pelo menos 2.000 anos. Primeiramente, vieram das bacias amazônicas com as dispersões territoriais dos grupos Tupi e, em seguida, dos próprios Guarani; intensificaram-se, provavelmente pressionados por um grande aumento demográfico e, também, a partir de motivação de fundo religioso, na busca por uma terra sem males. Esses grupos passaram a ocupar o interior e litoral dos estados do Paraná e São Paulo, além do Paraguai, do Uruguai e da Argentina (LADEIRA, 2001; SCHADEN, 1974; MELIÀ, 1988a).

Quando os invasores colonizadores chegaram ao continente, havia entre um a dois milhões de Guarani. Embora essa população tenha sido reduzida drasticamente ao longo dos séculos, ainda hoje, é o maior povo indígena na América do Sul, presente na Bolívia, Argentina, Paraguai e Brasil (MELIÀ, 1988a). Em todo continente, atualmente, são mais de 280.000 pessoas, no Brasil são, aproximadamente, mais de 80.000 pessoas (PEREIRA, 2016).

Mesmo após séculos de contatos, a existência dos Avá-Guarani na região da Bacia do Prata permanece. A Guerra do Paraguai (1864-1870), entre a Argentina, o Uruguai e o Brasil contra o Paraguai, vencida pelo Brasil, deixou marcas na dinâmica social dos Guarani. Isso porque deu início à ocupação e colonização do interior do país, principalmente no território dos Guarani, no oeste do Paraná. Com o estabelecimento da Companhia Matte Laranjeira, em 1882, juntamente com a exploração da madeira na região e, mais tarde, o estabelecimento da pecuária extensiva, a população Guarani é novamente expulsa e reduzida em espaços diminutos.

Em diversos relatos, registramos tais fatos nas narrativas do xeramoi e da xejary'i da aldeia Yvara ty Porã:

Bom, eu sou daqui mesmo, meus pais são tudo daqui. Daí é que veio aquela companhia que trabalhavam na erva e quando essa companhia [Matte Laranjeira] chegou já tinha nascido aqui, depois que nasci em dois dias meus pais me levaram para o Mato Grosso do Sul. Desde então, cresci em Mato Grosso do Sul, isso meus 
pais contaram antes de morrer, que eu era daqui mesmo. Então, por isso, retornei pra cá, e aqui mesmo meus parentes morreram, meus avós nasceram todos aqui. Desde então, não posso sair daqui porque meus parentes faleceram aqui foram enterrados aqui, mas não sei onde e exatamente, quando eles ficaram doente só meus pais vieram ver, eu não vim junto, só depois que sepultaram os meus pais voltaram para o Mato Grosso do Sul, quando eles chegaram lá, logo, faleceram e foram sepultados no Mato Grosso do Sul. [...]. Meus pais conheciam tudo até Curitiba, então, eu voltei para cá, mesmo velho, por isso procurei de novo onde meus parentes foram enterrados, porque quando morrer quero ser enterrado onde meus parentes foram; isso me preocupa porque quando morrer não poderei ser enterrado na terra dos outros (fazendeiros), não posso ser enterrado na terra dos outros, e procurei voltar aqui, queria morrer em paz aqui na terra onde nasci.

A saída compulsória dos Guarani em diversos momentos da história nacional não cessou; no início do século seguinte, a marcha para o Oeste, estimulada no governo de Getúlio Vargas (1938), pretendia explorar o interior do país, logrou grande êxito para os exploradores da erva-mate e da madeira, aos colonos e a projetos agropecuários, não para os Guarani; assim como a criação da Colônia Agrícola de Dourados, em 1943, com a ida de militares e colonos para a região, que, neste período, como na década de 1980, não deixou escolhas, ou fugiam para outros locais, como Paraguai, Bolívia e Mato Grosso do Sul ou trabalhavam em regime quase escravo nas lavouras e no corte da madeira (CALEIRO, 2016).

As ofensivas avançaram com a criação do Parque Nacional do Iguaçu (PNI), em 1939, o qual não permitia a presença de humanos. Com o advento do golpe militar em 1964, até o início da década de 1980, a mecanização da agricultura e dos monocultivos de soja, milho e cana de açúcar agravaram a situação dos Guarani e ocorreram novas fugas para outras regiões. O relato de um xeramoi e uma xejary'i reitera a literatura: “Quando os brancos chegaram, capturaram, mataram muitos índios, mataram muitos parentes meus, eu tinha uma relação de quais dos meus parentes foram assassinados, passei para meu neto e está com ele, essa relação, ele que tem todos os nomes".

Não bastassem as décadas de deslocamentos forçados, consentidos pelo Estado brasileiro, a partir de meados dos anos 1970 e início de 1980, a construção da Usina Hidrelétrica Binacional de Itaipu, provoca aos Avá danos irreparáveis, como: a desapropriação de diversas aldeias e a submersão de parte da cultura material e imaterial dos seus ancestrais, após a formação do lago de Itaipu. Nesse momento, diversas famílias migram para o Paraguai, Mato Grosso do Sul, Bolívia e Argentina em busca de sobrevivência, diante das ameaças de morte, assassinatos e retiradas forçadas de famílias inteiras dos locais, objetos de disputas (COMISSÃO GUARANI YVYRUPA, 2017). 
Diversos municípios da região oeste do Paraná, bem como outros no Paraguai, foram afetados pela construção da Hidrelétrica Binacional de Itaipu, sendo que alguns tiveram mais de $80 \%$ do seu território alagado (ALCÂNTARA, 2019).

Nas lembranças de uma xejary'i, esses trágicos episódios são recordados:

Eu vim da Jacutinga, quando encheu a gente saiu de lá, viemos para Oco'y, nos vivíamos assim: não tínhamos terra, vivíamos a trabalho por aí. Então, voltamos a Jacutinga para ficar, e lá fizemos a luta para ganhar essa terra onde estamos, sofremos muito para isso, se fosse pra contar vamos passar dias falando, sofremos muito com meus filhos que agora estão crescidos, isso que tenho a dizer: o sofrimento que passamos.

Nesse período, a visão propagada com o intuito de desqualificá-los era a de que seriam nômades, "paraguaios", jamais "donos originários" dos territórios em disputa, visão perpetuada até os dias atuais. Em parte porque a mobilidade, o trânsito entre aldeias, é uma das principais características dos Guarani que se movimentam em seu território tradicional, delimitado e, raramente, abandonam por completo as suas antigas aldeias. Por outro lado, porque não lhes restava alternativa a não ser fugir (LADEIRA, 2001).

Tais deslocamentos em busca de um "lugar melhor para viver" fazem parte de uma estratégia de resistência, muitas vezes, forçada sob as pressões externas, noutras vezes por oferecer também, e, principalmente, momentos de intercâmbios de sementes, mudas, de fortalecimento de alianças políticas e sociais, por exemplo, por meio do casamento, de reflexão a respeito dos problemas enfrentados nas comunidades.

As pressões externas influenciam na organização social, política, econômica e cultural dos Guarani que se desenvolve no tekoha, território, local onde o modo de ser Guarani pode ser vivenciado. "El tekohá significa y produce al mismo tiempo relaciones económicas, relaciones sociales y organización político-religiosa, que son esenciales para la vida guaraní: sin tekohá no hay tekó, sin territorio no hay vida guarani". (PEREIRA, 2016, p.12).

Reiteramos essa asserção durante a entrevista com um jovem vice-cacique, 26 anos de idade, da aldeia Araporã, no município de Santa Helena "A terra demarcada é importante para ter cultura, sem terra, sem local, não tem cultura, precisamos ter dignidade. A família espera dignidade".

A maior parte dos tekoha foi suprimida pela exploração e desapropriação indevida, tanto pelo Estado brasileiro quanto pelas empresas do agronegócio de soja, celulose, cana de 
açúcar, mineradoras e empreendimentos turísticos. O esbulho territorial a que vêm sendo expostos os levam a viver em condições subumanas à beira de rodovias, em territórios diminutos e/ou em áreas nas quais não há possibilidade de cultivo sequer dos alimentos tradicionais, como milho, amendoim, batata, entre outros (COMISSÃO GUARANI YVYRUPA, 2017).

As saídas forçadas dos seus territórios tradicionais estão presentes nos relatos dos jovens: "Meu avô saiu corrido daqui para o MS por causa dos brancos. Fugiram para o Paraguai, Bolívia e Mato Grosso do Sul. Meus avós falavam sobre a volta à região, sobre a retomada, pois a área em que estamos é um antigo cemitério Ava". E, também, nas lembranças dos xeramoi e xejary'i:

\footnotetext{
É importante [a terra] para nós, precisamos dela porque foi nosso Deus Tupã que deu para nós, guarani, aqui no Paraná. Antes não tinha esses brancos aqui, antigamente não tinha não se via os brancos, o que se via aqui era os Guarani e Guarani mbya, só tinha esses dois, viviam nessa imensidão de matas, era tudo mato mesmo, era muito grande a mata, tinha muitos guarani e mbya, e muitos morreram de diarreia, sarampo. Logo, vieram os brancos e os mataram também, por causa dessa matança que se espalharam por aí e foram para o Mato Grosso do Sul.
}

Concorrentemente ao agravamento da sua situação com a construção de Itaipu (1975-1982), ocorria no Brasil o fortalecimento e a organização dos povos indígenas, apoiados por parte da sociedade civil organizada, o que resultou na sua inclusão na Constituição Federal de 1988 e, consequentemente, num maior empoderamento e autonomia. Conforme o movimento indígena nacional vai se consolidando, os processos de retomada dos territórios tradicionais, em diversas regiões do país, iniciados na década de 1990, começam a se intensificar a partir dos anos 2000 na região do oeste do Paraná. É neste período, também, que a ideia de juventude indígena passa a ser mais discutida, conforme veremos a seguir.

\section{Os jovens Avá-Guarani}

A sociedade não indígena definiu, no Estatuto da Juventude (BRASIL, 2013), que são jovens os que possuem entre 15 a 29 anos de idade, com variações entre jovens adultos e jovens adolescentes. Aproveitando essa definição, nos valemos desse referencial em diversos momentos neste texto aos nos referirmos aos entrevistados como jovens. De acordo com o 
censo do IBGE, em 2010 havia 896 mil indígenas no Brasil, destes 441 mil eram jovens ou crianças (OLIVEIRA, 2017).

Mas, e para os indígenas quem são os jovens, quem são esses sujeitos sociais, quais seus papéis sociais? Na medida em que a sociedade se transforma, as mudanças sociais, econômicas, políticas, ambientais e tecnológicas, também perpassam os jovens indígenas, os quais passam a querer ter acesso a artigos eletrônicos, às redes sociais, ao lazer, à educação, à saúde, a bens de consumo, como roupas, sapatos, aparelhos eletrônicos, como qualquer outro jovem. Todavia, este mesmo jovem traz consigo memórias, modo de ser e viver bastante distintos das do jovem não indígena.

Antes do contato permanente com os não indígenas, do acesso à tecnologia, da entrada de políticas e programas sociais públicos, das políticas de assistência social, saúde e educação que trouxe aos povos originários renda e/ou salários nas aldeias, alterando a dinâmica cotidiana, tínhamos os rituais de iniciação, que marcavam a transição da infância para a fase adulta, embora alguns povos ainda mantenham os ritos de passagem. Hoje, no entanto, diante das transformações sociais, econômicas políticas, culturais e ambientais que, também perpassam e afetam a dinâmica dos povos originários, por um lado os obriga a viver em terras exíguas, sem área para plantio ou fauna e flora para explorar. Ou seja, se antes os meninos estavam aptos a sustentar a família com os recursos extraídos da natureza e as mulheres a cuidar dos filhos, da roça e a cozinhar, atualmente, isso não é mais tão corriqueiro, visto que tão pouco há alimentos para caçar, plantar e cozinhar.

A capacidade de transitar entre dois mundos, no Guarani e no do karaí, em luta por seus direitos coletivos, forja um espaço social que leva a reflexão a respeito do seu papel, enquanto sujeito que traz consigo a memória do seu povo. A esse engajamento podemos atribuir, sobretudo aos mais velhos, a responsabilidade de transmitir a cultura e a história de luta - a partir do resgate e da transmissão da memória coletiva - aos mais jovens, dando maior sentido à sua existência.

Embora a definição de juventude varie conforme a sociedade em que está inserido o jovem, nas comunidades indígenas essa ideia não ocorria até pouco tempo. A categoria juventude, jovem indígena, ainda recente no debate acadêmico, justamente por ser incipiente, oportuniza a discussão a respeito da existência deste "grupo", pois são esses 
sujeitos sociais, em diversas situações, quem levam a voz do seu povo para fora dos limites da aldeia.

Essa categoria, ainda em construção, segundo Sant'Anna apud Oliveira (2017), pode ter surgido ainda na ditadura militar, a partir da criação da guarda rural, onde era necessário ter uma determinada idade para tal função. Podem ter influenciado no surgimento desta categoria, a educação, iniciada na educação básica, mas, também, a sua presença nas universidades, agora são estudantes. E ainda, a partir da organização dos movimentos indígenas que, surgidos aos finais dos anos 1970, se consolidaram nas décadas seguintes, abrindo caminho para o surgimento de diversos grupos e coletivos de jovens indígenas, que passaram a assumir responsabilidades dentro dos seus grupos e se tornaram sujeitos autores da sua história e da do seu povo; bem como reflexo da migração dos indígenas para as cidades, da influência dos meios de comunicação e do crescimento populacional dessa faixa etária (OLIVEIRA, 2017).

Os jovens, quando questionados sobre o seu papel na comunidade e a perspectiva para o futuro, embora encontrem contradições e inquietações no caminho, como: a ausência de perspectivas futuras, os poucos investimentos na educação e na saúde indígena, os altos índices de suicídio, o uso abusivo de drogas e álcool, são uníssonos em reiterar que a sua participação nas reuniões comunitárias, onde os moradores compartem das dificuldades e dos eventos cotidianos, e ainda, em encontros regionais, nacionais e transnacionais nas chamadas $a t y^{2}$, no movimento indígena, principalmente, nos rituais na opy e a articulação por meio das redes sociais, o ingresso nas universidades são estratégias de resistência e fortalecimento da luta do seu povo.

Nos relatos dos jovens, as histórias contadas pelos xeramoi e pelas xejary'i thes imputam responsabilidade tal, que nem sempre estão à altura de responder, haja vista as pressões externas e internas que enfrentam para sobreviver. O fato é que não lhes são dadas condições para tal, haja vista as contradições e inquietações no caminho, como: a ausência de perspectivas futuras, os poucos investimentos na educação e na saúde indígena, os altos índices de suicídio, o uso abusivo de drogas e álcool.

\footnotetext{
2 Termo em Guarani faz referência a grande reunião, encontro. Na década de 1980, os Guarani passaram a se organizar, assim como indígenas em outras regiões do país, e deram início a Aty Guassu, grande assembleia Guarani. Em 2006, foi criada a Comissão Guarani Yvyrupa, a qual reúne lideranças Guarani de todo o Brasil para discutir sobre políticas públicas.
} 

Yvyrupa (2017):

A pesquisa conseguiu identificar catorze casos de suicídio cometidos pelos Ava Guarani de Guaíra e Terra Roxa entre 15 de julho de 2010 e 6 de outubro de 2016. As principais vítimas são jovens: dez indígenas que tiraram a própria vida tinham menos de 20 anos de idade, outro tinha 21 anos e, outro, 22 (p. 190).

Importa registrar que, lamentavelmente, durante a pesquisa de campo dois jovens cometeram suicídio em aldeias distintas da região.

O fato de os jovens vivenciarem essas e tantas outras situações de violações de direitos, leva-os a intensificarem sua participação nos rituais na opy, nas reuniões comunitárias, em encontros regionais, nacionais e transnacionais nas chamadas aty no movimento indígena, na articulação por meio das redes sociais, no ingresso nas universidades. Dessa forma, o papel social do jovem adquire importância estratégica na resistência e no fortalecimento da luta do seu povo.

Nas narrativas dos jovens, a apropriação da memória coletiva, enquanto instrumento de luta é relembrada desde a história de invasão de seus territórios tradicionais na região do Mato Grosso do Sul e Oeste do Paraná, onde se concentra a maior parte da população Guarani no Brasil:

Daqui da região correram para todo lado pro Paraguai, Mato Grosso do Sul, Bolívia, correndo das guerras. Daí nós viemos para cá e vimos que era verdade mesmo o que falava nossos bisavôs: vão que é verdade, vocês vão ver o lugar onde foi executado, onde tinha uma guerra, onde tem a tábua que foi enterrada e que tinha um cemitério e vocês vão sentir na pele e no coração o que fizeram com a gente, os brancos, os portugueses. Daí desde então os Guarani se reuniram e ficaram aqui na região e em Terra Roxa. Nós retomamos a região que era usada pelos antigos.

Nesta perspectiva, "a memória na qual cresce a história, que por sua vez a alimenta, procura salvar o passado para servir ao presente e ao futuro. Devemos trabalhar de forma que a memória coletiva sirva para a libertação e não para a servidão dos homens" (LE GOFF, 2003, p. 471).

A apropriação da memória coletiva, além de fundamental à identidade coletiva ou individual, é um instrumento de luta e poder (LE GOFF, 2003), por meio do qual reitera a sua existência e dá novo sentido ao jovem: o de lutar e resistir frente às opressões dos karaí que não cessam. 
A articulação entre as lembranças resgatadas a partir das memórias dos mais velhos e o papel social da juventude Avá, é sintetizada numa das entrevistas realizadas com dois jovens da aldeia Jevy:

É importante para o jovem participar da retomada porque aí eles têm a noção do que vem pela frente, porque os mais velhos já estão cansados de viver nessa situação, os que são mais novos têm mais fôlego de lutar nessas áreas de conflito para poder avançar em cima, para poder aprender como estão trabalhando as lideranças, os que são mais velhos, para ouvir e aprender, para poder ser um líder, para poder lutar a favor da família porque ele vai ser adulto vai ter criança. Os mais velhos falam que [...] por isso é importante que todos os jovens e crianças participem da reunião, de encontros.

Compreendemos que esta nova categoria, jovem indígena, muito tem de antigo, na perspectiva da resistência ancestral que traz consigo o portador da memória coletiva. Foi e é por meio dos ensinamentos, das histórias, da cultura transmitidas pelos mais velhos, das suas próprias vivências cotidianas, que os jovens criam estratégias para existir, ao mesmo tempo em que constroem um novo espaço social, até então, desconhecido. As narrativas em sociedades orais, ou em vias de escrita, e a história dos acontecimentos, ficam sob a responsabilidade dos chamados homens-memória, dos que guardam a história do povo, sua origem, os principais acontecimentos (LE GOFF, 2003).

Em todas as narrativas, os jovens mencionaram a importância dos ensinamentos dos mais velhos que os fortalecem para continuar na luta. Os jovens Avá-Guarani mantêm viva em sua memória as histórias transmitidas pelos xeramoi e pelas xejary'i, segundo eles, são elas que lhes contam quem são, de onde vieram e qual seria seu propósito na vida:

Antigamente essa terra era nossa mesmo. Minha vó correu daqui e foi pro MS. Antigamente era tudo moradia dos índios. Dai começou os brancos a chegar, a falar que isso aqui é nosso e a comprar a terra. Daí vem outro fazendeiro e fala isso aqui é nosso. Daí os antigos saíram correndo. Fazer o que? Daí passou o tempo e voltamos a nossa terra de novo. Por isso muitos fazendeiros falam que a gente vem do Paraguai, mas não é. Nós voltamos para nossa terra. Falam que a gente veio atrás de cesta, de aposentadoria, mas não é isso, voltamos a nossa terra. [...] Como o meu bisavô falava pra gente e a gente sentava e escutava que essa parte da região do Paraná, entre Guaíra, que a beirada era tudo aldeia, ele falava chorando: que tinha uma guerra que vinha exterminando todo mundo, nos ouvimos essa notícia e corremos. E acabou tendo mesmo; matou quase todos. Um dia meu bisavô falava: um dia as nossas crianças vão acordar e falava pra gente: vocês tem uma terra naquela região que é nossa, também falou que os brancos. 
A importância dada à cosmovisão Guarani transmitida, principalmente, pelos xeramoi e xejary'i, é decisiva no fortalecimento das gerações mais novas para a continuidade da luta dos seus ancestrais. A transmissão da cosmovisão Guarani termina por fortalecer e compor as estratégias de resistência desse povo.

Nesse sentido, a participação e iniciação dos jovens em rituais de dança e cantos na língua são momentos de transmissão dos ensinamentos dos mais velhos e de reafirmação cultural para os mais jovens. Os ñanderu (pajés) se reúnem na opy, para entrar em contato com as divindades e dar sentido à existência e resistência do povo. Embora a transmissão do ñandereko não aconteça exclusivamente na opy, haja vista que no cotidiano Guarani, a sua visão de mundo, o modo de se relacionar entre si e com os não indígenas, com a natureza são fortalecidos sistematicamente. "No es sólo religión, sino filosofía, poesía, teología y fundamento de su identidad. Los rituales guaraníes constan generalmente de canto y danza; son oración danzada, danza que es oración" (PEREIRA, 2016, p. 17).

A participação dos jovens nos grupos de canto e dança, também sinaliza a relevância dada à dança ritual pelos Avá e a organização política de resistência e enfrentamento dos jovens aos sortilégios a que estão expostos. Conforme Melià (1988a):

\footnotetext{
Manteniendo la danza o revitalizándola, los chamanes reactualizaban de hecho tanto la mitología tradicional como la propia institución chamánica ligada con ella, en un intento por fortalecer todo el sistema cultural guarani. De ahí su importancia como recurso en la lucha anticolonial (p. 118).
}

Os grupos de jovens e, também os de dança e canto são, notadamente, políticos com vistas à organização interna e externa dos jovens indígenas que articulam ações, eventos e discussões a respeito da situação dos territórios no oeste do Paraná, bem como no movimento nacional indígena, representam resistência e enfrentamento, a partir dos ensinamentos dos mais velhos aos mais jovens, enquanto parte das estratégias de luta e sobrevivência. Podemos compreender o papel político e social da dança ritual que, além da cosmovisão Guarani, como um modo de fortalecimento e transmissão da cultura:

Un problema que a todos preocupa; un peligro que amenaza al grupo, aunque sólo sea en la fantasia del payé; una epidemia; una empresa común; a veces, una simple sensación de malestar general inexplicable, y hasta el mero placer del espetáculo, reúne a los Apapokúva en sua casa de danza (MÈLIA, p.119, 1988a, apud Nimuendajú, 1978). 
O transitar no mundo dos karaí e no Avá, realizado frequentemente, impõe aos jovens desafios, o rearranjo do seu cotidiano, ao passo que está na Opy recebendo os ensinamentos dos mais velhos, fortalecendo a sua cultura, resgatando a memória, também está nas universidades, nos grupos de jovens que abrem portas ao movimento indígena para além da aldeia, lócus privilegiado, imputam-Ihes responsabilidades que não tinham outrora.

Os sortilégios a que são expostos o povo e, por conseguinte, os jovens Avá-Guarani, os incumbem de repensar diferentes estratégias para re-existir e resistir por séculos em seus territórios tradicionais, palco do etnocídio dos seus ancestrais, todavia não foi, e não é, em vão. Não sucumbir a esses processos históricos de violência contra si e seu povo, vivenciando a sua cultura, seu modo de vida, sua cosmovisão, seu ñandereko, mesmo à beira das estradas ou confinados em territórios diminutos, demonstra a força e a capacidade de resistir e reexistir do Guarani impressa em sua memória ancestral relembrada nos sofrimentos e nos ensinamentos dos antepassados.

\section{Considerações}

Ser jovem indígena no Brasil é, sobretudo, superar desafios cotidianos propagados desde o uso abusivo do álcool e das drogas, da falta de perspectiva futura, de oportunidades de trabalho digno, de ter alternativas para o lazer, de acessar educação e saúde de qualidade, de se compreender enquanto parte de um meio ambiente em constante degradação, de não ter acesso a tecnologias da informação e a bens de consumo.

Somam-se a esses desafios, sob a ótica dos jovens indígenas, mais de 500 anos de reiterados processos de luta em prol da sobrevivência, da liberdade, do respeito e da dignidade, que marcaram a sua existência enquanto ser humano, forçando-os a repensar novas formas de re-existir no território.

Desde os primeiros contatos dos Avá-Guarani com os não indígenas, a sua existência foi profundamente alterada e desafiada, mas não aniquilada, conforme desejavam e desejam os invasores de seus territórios. A transmissão do modo de ser Guarani, repousada na memória, detém poder em quem a possui (LE GOFF, 2003), assim sendo, os jovens se armam desse elemento em prol do coletivo, se fortalecem e se organizam local, regional, nacional e internacionalmente e resistem às situações de opressão ordinárias. 
Em seus relatos, a resistência está fortemente amparada pela transmissão da cosmovisão, dos costumes dos xeramoi e das xejary'i aos jovens, providencial no ato de existir, de sobreviver todos os dias, ainda que no limite da humanidade, em situações degradantes e, por vezes, humilhantes.

A falta de educação e saúde adequadas, os impulsiona a buscar o conhecimento nas universidades para melhorar as suas condições e da comunidade e conhecer mais os seus direitos; o pouco acesso que têm a tecnologias da informação usam para se articular com jovens de outros povos e regiões e fortalecer cada vez mais o movimento indígena; a degradação ambiental que veem e sentem cotidianamente, agravada pelo agronegócio, passa pela tentativa de recuperação em áreas diminutas, por meio de pequenos e limitados plantios, que não os deixa sucumbir à fome; o uso abusivo de drogas e álcool, muitas vezes, os leva a refletir sobre como se fortalecer enquanto grupo.

Ser parte da maior nação indígena é se reinventar, é saber o porquê da sua existência, é enfrentar as lutas colocadas cotidianamente, é defrontar a política de Estado genocida, é respeitar as pessoas mais velhas por seus saberes, seus conhecimentos, as crianças por sua ingenuidade e pelas incertezas que o futuro lhes reserva, é respeitar o meio ambiente tal qual o humano, é ter a certeza de que nada pertence, tudo é transitório, é saber por que "re-voltar a um território que é nosso", jovem Avá.

\section{REFERÊNCIAS}

ALCÂNTARA, Gustavo [et al.]. AVÁ-GUARANI: a construção de Itaipu e os direitos territoriais. Brasília: ESMPU, 2019. Disponível em: http://escola.mpu.mp.br/publicacoes/obrasavulsas/e-books/ava-guarani-a-construcao-de-itaipu-e-os-direitos-territoriais. Acesso em abr 2019.

AMARAL, Gustavo Gurgel do. Geografia da Re-Existência: conhecimentos, saberes e representações geográficas na educação escolar indígena do povo Oro Wari - RO. Tese de doutorado. UFPR. Curitiba, Paraná, 2016.

BRANT DE CARVALHO, Maria Lúcia. Da terra dos índios aos índios sem terra. Tese de doutorado. USP. São Paulo, SP, 2013.

BRASIL. Estatuto da Juventude. Lei n.12.852, de 5 de agosto de 2013. Disponível em: http://legislacao.planalto.gov.br/legisla/legislacao.nsf/Viw_Identificacao/lei\%2012.8522013 ?Opendocument. Acesso em: ago. 2018. 
CALEIRO, Manuel M. Território guarani: um espaço de resistência. In: SOUZA, Carlos F. M. de. (Coord.); MAMED, Daniele de Ouro; CALEIRO, Manuel Munhoz; BERGOLD, Raul Cezar (Orgs.). Os Avá-guarani no oeste do Paraná: (re) existência em Tekoha Guasu Guavira. Curitiba, PR: Letra da Lei, 2016.

COMISSÃO GUARANI YVYRUPA. Relatório de Violações de Direitos Humanos no Oeste do Paraná. 2017. Disponível em: http://www.yvyrupa.org.br/blog/2017/08/16/cgy-lancarelatorio-sobre-violacoes-de-direitos-humanos-contra-os-ava-guarani-no-oeste-do-parana/. Acesso em: ago 2018.

GOUVÊA, J. B., LÓPEZ CABANA, R. P., \& ICHIKAWA, E. Y. (2018). As histórias e o cotidiano das organizações: uma possibilidade de dar ouvidos àqueles que o discurso hegemônico cala. Farol - Revista de Estudos Organizacionais e Sociedade, 5(12), p. 297-347.

HALBWACHS, Maurice. A memória coletiva. São Paulo: Vértice, Editora Revista dos Tribunais, 1990.

ICHIKAWA, Elisa Y.; SANTOS, Lucy W. Contribuições da história oral à pesquisa organizacional. In: Silva, Anielson B. da; Godoi, Christiane K.; Bandeira-de-Mello, Rodrigo (orgs.). Pesquisa qualitativa em estudos organizacionais: paradigmas, estratégias e métodos. Saraiva, 2006.

ICHIKAWA, Elisa Y.; SANTOS, Viviani T. Representações sociais, história e memória: possíveis contribuições para os estudos organizacionais. In: Revista Eletrônica Gestão \& Sociedade. v.12, n.31, p. 2213-2231 Janeiro/Abril - 2018.

LADEIRA, M. I. Espaço geográfico Guarani-Mbyá: significado, constituição e uso. Tese de Doutorado - Universidade de São Paulo. São Paulo: USP, 2001.

LE GOFF, Jacques. História e memória. Tradução Bernardo Leitão [et al.]. Campinas, SP: Editora da UNICAMP, 2003.

LIMBERT, Rita de Cássia A. P. Existência indígena: resistência em busca da (re)existência. Cadernos de Estudos Culturais. vol.7, n.13, 2015. Disponível em:

http://seer.ufms.br/index.php/cadec/article/view/3414. Acesso em: fev 2019.

LINI, Priscila. Entrevista realizada com Bartolomeu Melià s.j. In: SOUZA, Carlos F. M. de. (Coord.); MAMED, Daniele de Ouro; CALEIRO, Manuel Munhoz; BERGOLD, Raul Cezar (Orgs.). Os Avá-guarani no oeste do Paraná: (re) existência em Tekoha Guasu Guavira. Curitiba, PR: Letra da Lei, 2016.p. 35-43.

MELIÀ, Bartolomeu. El Guaraní conquistado y reducido, ensayos de etnohistoria. 2.ed. Assunção, Paraguay: Centro de Estudios Antropologicos de la Universidad Católica N.S. de la Asunción, 1988a. Una nación, dos culturas. Assunção, Paraguai: RP Ediciones, CEPAG, 1988b. 
OLIVEIRA, Assis da C. Mobilização social de jovens indígenas e a construção intercultural dos direitos da juventude no Brasil. In: Juventudes Indígenas: estudos interdisciplinares, saberes interculturais conexões entre Brasil e México.

OLIVEIRA, Assis da C.; RANGEL, Lucia Helena. Juventudes Indígenas: estudos interdisciplinares, saberes interculturais conexões entre Brasil e México. Rio de Janeiro: Epapers, 2017. Disponível em: http://www.promovide.febf.uerj.br/biblioteca/nepie/livrojuventudes-indigenas.pdf. Acesso em: nov 2018.

PEREIRA, Levi M.; COLMAN, Rosa; MACHADO, Flávio V (Coord.). Mapa Guarani Continental. Campo Grande, MS: Equipe Mapa Guarani Continental, 2016. Disponível em:https://bd.trabalhoindigenista.org.br/sites/default/files/MGC2016CuadernoEspanol_0.pdf. Acesso em: ago 2018.

RANGEL, Lucia H.; VALE, Claudia Netto. Jovens indígenas na metrópole. Revista Eletrônica Ponto \& Vírgula. vol.4, n.4, 2008. p. 254-259. Disponível em: https://revistas.pucsp.br/pontoevirgula/article/view/14190. Acesso em: set 2018.

SCHADEN, Egon. Aspectos Fundamentais da cultura Guarani. 3.ed. São Paulo: EDUSP, 1974. YATES, Frances A. A arte da memória. Campinas, SP: Editora da Unicamp, 2007. 